\title{
Benefit Class of Second-line Anti-diabetic Medication on Types of Dementia in Type 2 Diabetes: A Nationwide Real-world Longitudinal Study
}

Won Jun Kim

Gangneung Asan Hospital, University of Ulsan College of Medicine

Jung Hyun Noh

Inje University Ilsan Paik Hospital, Inje University College of Medicine

Kyungdo Han

College of Medicine, Catholic University

Cheol-Young Park ( $\triangle$ cydoctor@chol.com )

Kangbuk Samsung Medical Center https://orcid.org/0000-0002-9415-9965

\section{Research}

Keywords: dementia in type 2 diabetes, thiazolidinedione (TZD), dyslipidaemia, hypertension

Posted Date: November 30th, 2020

DOI: https://doi.org/10.21203/rs.3.rs-113357/v1

License: (c) (i) This work is licensed under a Creative Commons Attribution 4.0 International License. Read Full License 


\section{Abstract}

\section{Background}

To investigate the association between treatment of anti-diabetic agents and dementia in type 2 diabetes mellitus using an extensive dataset from the Korean National Health Insurance System and Health Screenings.

\section{Methods}

After excluding anyone younger than 40 , those taking no anti-diabetic medications within $1 \mathrm{yr}$ of the examination, anyone diagnosed with dementia before the examination or its development within $1 \mathrm{yr}$ of the examination, and those with missing data, 1,578,322 individuals with diabetes prescribed an anti-diabetic agent (metformin (Met), sulfonylurea (SU), thiazolidinedione (TZD), dipeptidyl peptidase-4 inhibitor (DPP-4i), meglitinide (Megl), alpha-glucosidase inhibitor(AGI) and/or insulin) between 2009 and 2012 were identified from the Korean National Health Insurance Service Database, where 701,193 individuals taking oral dual therapy were tracked until 2017. All-cause, Alzheimer's (AD) and vascular dementia (VaD) were investigated by oral dual therapy. Adjustments were made for age, sex, income, diabetes duration, hypertension, dyslipidaemia, smoking, drinking, exercise, BMl, glucose level and estimated glomerular filtration rate.

\section{Results}

Compared with dual therapy with Met + SU, dual therapy with Met + DPP-4i, Met + TZD, and SU + TZD, was associated with lower all-cause dementia (HR (95\% $\mathrm{Cl})=0.904$ (0.879-0.929), 0.804 (0.767-0.844), and 0.962 (0.929-0.996), respectively) and $\mathrm{VaD}(\mathrm{HR}(95 \% \mathrm{Cl})=0.865(0.806-0.928), 0.725(0.64-0.822)$, and 0.911 (0.833-0.995), respectively) after adjustment. Also, compared with the group treated with Met + SU, those treated with Met + DPP-4i and Met + TZD were associated with a significantly lower risk of $A D(H R(95 \% \mathrm{Cl})=0.922(0.894-0.951)$ and $0.812(0.77-0.857))$ except for SU + TZD $(H R(95 \% \mathrm{Cl})=0.971(0.934-$ 1.01)). Dual therapy with TZD was associated with a significantly lower risk of all-cause dementia, $A D$, and VaD than nonusers of TZD (HR $(95 \% \mathrm{Cl})=0.918$ (0.892-0.944), 0.925 (0.896-0.955) and 0.859 (0.798-0.924), respectively).

\section{Conclusions}

Adding TZD or DPP-4i instead of SU as second-line treatment in combination with first-line Met may be considered for delaying or preventing dementia. Also, TZD users relative to TZD non-users on dual therapy had a significantly lower risk of all types of dementia.

\section{Background}

The incidence of type 2 diabetes mellitus (T2D) is increasing rapidly and it is a growing global health problem. The International Diabetes Foundation (IDF) reports there were 366 million adults with diabetes worldwide in 2011 and there will be 552 million by 2030 [1]. To control the glucose status in T2D and decrease diabetes complications, the emergence of new anti-diabetic medications has occurred over the last two decades. Along with the discovery of heterogeneity in diabetes pathogenesis [2], the number of patients on dual and triple combination therapy has steadily increased [3-4]. According to the guidelines for diabetes management, metformin (Met) is recommended as first-line therapy, and various other oral and injectable pharmacological agents and can be combined with it, considering their efficacy, safety, side effects, costs, and co-morbidities such as atherosclerotic cardiovascular disease, heart failure or chronic kidney disease [5].

T2D is well known one of the risk factors to increase the risk of dementia. Based on the epidemiological Rotterdam study by Ott et al., T2D is supposed to nearly double the risk of dementia [6-8]. However, currently, the management of dementia is mainly symptomatic therapy with little effect on delaying its progression or preventing it. A 2013 meta-analysis of 28 prospective observational studies suggested that patients with diabetes are at higher risk of all-cause dementia, Alzheimer's (AD), and vascular dementia (VaD) [9]. T2D shares common pathophysiological components with dementia, such as cardiovascular risk factors, glucose toxicity, insulin resistance and inflammation [10]. Therefore, anti-diabetic therapy has become an interesting approach to preventing dementia.

Although there was a report stating that there is no evidence supporting a glucose-lowering strategy to delay or prevent dementia [11], diabetes medications may influence the development and progression of cognitive decline in humans with diabetes [12]. Recently, eight human epidemiologic retrospective observational studies with more than 3 years of follow-up have shown associations between T2D medications and dementia risk [13-20, see S1 Table]. By using active comparative medication, the risk of dementia was decreased in metformin (Met) vs sulfonylurea (SU), DPP4 inhibitor (DPP-4i) vs SU, and Met + thiazolidinediones (TZD) vs Met + SU [13-15]. By using ever-users vs never-users, ever-users of Met, TZD and DPP-4i diminished the risk of dementia more than never-users [17-19]. However, in real-world clinical settings, various drug combinations exist. Only Bohlken J, et al. revealed the benefit of Met, TZD and Met + SU and the disadvantage of insulin for reducing the risk of dementia in various mono- and dual therapy combinations [16]. Also, there are few reports that evaluated dementia subclasses, and DPP-4i showed inconsistent results for AD and VaD [14, 19].

Therefore, the aim of this study was to analyse the association between oral dual therapy with glucose-lowering drugs and various types of dementia.

\section{Methods}

\section{Study Design, Setting, and Populations}

We used a population-based retrospective observational cohort study established by the National Health Insurance Service (NHIS) of Korea between 2009 and 2012, traced to 2017. NHIS is a compulsory single-payer national healthcare coverage system and has covered approximately 50 million population of South 
Korea since 1989. Detailed information about the NHIS claim database has been made available [21]. Briefly, the NHIS database has access to the medical records of the entire Korean population and they undergo general health screenings every 2 years. The NHIS claims database contains information on diagnoses (International Classification of Diseases, 10th revision (ICD-10) code), prescription records, and demographics. The NHIS claim database includes major risk factor variables, but lacks many medical records and laboratory tests such as body size, brachial blood pressure and fasting blood chemistry data. Therefore, we combined the NHIS claims database with the health screening examination dataset.

From the NHIS claims database, we extracted 2,703,713 people among those who had undergone health check-ups, including those who had a blood sugar level of 126 or higher at their health screening examination or those who were prescribed anti-diabetes medication and were given a diagnosis of T2D (ICD-10 code, E11 to E14) between January 2009 and December 2012. The exclusion criteria are as follows: age < 40, no anti-diabetic medication within 1 yr of the examination, those who had developed dementia before the examination or developed dementia within $1 \mathrm{yr}$ of the examination, and those with missing data (See Figure 1). The study cohort was followed up to 2017.

The study therapies were defined as follows: Met, SU, TZD, DPP-4i, Meglitinide (Megl), a-glucosidase inhibitor (AGI) and insulin because the use of these medication classes was common at the time of the baseline of the study (in contrast to other drug classes such as SGLT-2 inhibitors and GLP-1 agonists). Among the 1,578,322 people who used anti-diabetic medications, there were many differences in baseline characteristics for each group with only an insulin regimen, oral monotherapy, oral dual therapy and triple therapy (Suppl Table 2). The association between anti-diabetic medications and dementia was investigated by stratifying with/without insulin treatment due to different baseline characteristics. Based on Korean guideline of diabetes management, Met has been usually used as first line pharmacotherapy to treat people with T2D. After preliminary analysis, we focused on the association between oral dual therapy and various types of dementia by comparing Met+SU group as reference group.

\section{Study Outcomes}

The primary outcome was the first diagnosis of all-cause dementia (ICD-10 codes, F00 03, F107, G30, G310, G311, G318 and a prescription of anti-dementia medication), AD (ICD-10 codes, F00, G30 and a prescription of anti-dementia medication), or VaD (ICD-10 codes, F01 and a prescription of anti-dementia medication).

\section{Covariates}

The study covariates included age at index date, gender, duration of diabetes, income, presence of hypertension, presence of dyslipidaemia, smoking, drinking, presence of regular exercise, body mass index, systolic and diastolic blood pressure, total cholesterol, fasting glucose, and estimated glomerular filtration rate.

\section{Statistical analysis}

Data are presented as the mean \pm SD for normally distributed continuous variables and as proportions for categorical variables. ANOVA was used to analyse the continuous variables, and the differences between nominal variables were compared with the chi-square test. Annual event rates are described as the number of events per 1000 person-years (PY). Hazard ratios (HR) and their corresponding 95\% confidence intervals (Cl) were calculated using Cox proportional hazard models for investigating the association between dementia and diabetes medication, after adjusting for age, sex, income, hypertension, dyslipidaemia, DM duration, smoking, drinking, exercise, BMI (body mass index), glucose and the estimated GFR (glomerular filtration rate). Subgroup analyses differentiated by multiple cardiovascular risk factors were subsequently performed. All P-values were two-sided, and a value $<0.05$ was considered statistically significant. Statistical analyses were performed using SAS version 9.4 (SAS Institute, Cary, NC, USA).

\section{Ethical Approval}

All subjects provided written informed consent, and this study protocol was approved by the Institutional Review Board of the Sungkyunkwn University School of Medicine/Kangbuk Samsung Hospital (IRB No. 2018-01-036) and the Institutional Review Board of of the NHIS (number: NHIS-2019-1-218) . Informed consent was waived by the IRB.

\section{Results}

Characteristics of Study Population

Among the 1,778,322 patients receiving diabetes medication, baseline characteristics according to the number of insulin and oral medications were presented in Suppl Table 2. A total of 701,193 patients with oral dual therapy were selected in the cohort, averaging 60.6 yr old. Patients in the SU + TZD group demonstrated a longer duration of diabetes and those in the Met + SU group showed lower income. The baseline characteristics of the each group were presented in Table 1.

\section{The association between oral anti-diabetic medication and dementia type in dual combination therapy}

Table 2 shows that people treated with Met + DPP-4i or Met + TZD versus those treated with Met + SU or other SU combinations were younger and had relatively shorter diabetes duration and relatively higher income. A total of 63,546 cases of any dementia were observed during the 6,050,444 person-years comprising the follow-up period. Compared with dual therapy with Met + SU, those treated with Met + DPP-4i, Met + TZD and SU + TZD therapy were associated with a lower risk of all-cause dementia, $\mathrm{AD}$ and $\mathrm{VaD}$ in the non-adjusted model. After full adjustments, compared with dual therapy with Met $+\mathrm{SU}$, Met + DPP-4i, Met + TZD and SU + TZD therapy were associated with a lower risk of all-cause dementia $(\mathrm{HR}(95 \% \mathrm{Cl})=0.904(0.879-0.929), 0.804(0.767-$ 0.844), and 0.962 (0.929-0.996), respectively) and $\operatorname{VaD}(\mathrm{HR}(95 \% \mathrm{Cl})=0.865(0.806-0.928), 0.725(0.64-0.822)$, and $0.911(0.833-0.995)$, respectively). Also, compared with the group treated with SU + Met, those treated with Met + DPP-4i and Met + TZD were associated with a significantly lower risk of AD (HR (95\% 
$\mathrm{Cl})=0.922(0.894-0.951)$ and $0.812(0.77-0.857))$ except for SU + TZD (HR (95\% Cl) = 0.971 (0.934-1.01)) (Table 3). However, in insulin combination, no combination of oral dual medications lowered the risk of dementia than Met + SU. However, combination oral dual therapy with insulin did not show significant results in lowering dementia (Suppl Table 3 and Suppl Table 4). Also, there were no significant results in oral triple therapy (Data not shown).

\section{The effect of TZD on oral dual therapy and the types of dementia}

When we included both lobeglitazone and pioglitazone in the category of TZD, TZD users showed a lower risk of dementia compared with nonusers of TZD on oral dual anti-diabetic medications (Table 4). After adjustment, compared with the nonusers of TZD, dual therapy with TZD was associated with a significantly lower risk of all-cause dementia, $A D$, and $\operatorname{VaD}(\mathrm{HR}(95 \% \mathrm{Cl})=0.918(0.892-0.944), 0.925(0.896-0.955)$ and $0.859(0.798-0.924))(\mathrm{Table} 3)$.

\section{Discussion}

This retrospective study, including more than 1,578,000 patients with T2D with long term follow-up (median follow-up 6.94 years), provided clinical evidence of the comparative effects of TZD and DPP-4i vs other second-line oral anti-diabetic medications on the risk all-cause dementia, AD, and VaD. Also, compared with that of Met $+\mathrm{SU}$, the dual combination of TZD without Met showed a significantly lower risk of all-cause dementia and VaD. However, there was no benefit of combination with insulin or the use of more than dual therapy to prevent dementia in this observational study.

In this study, any combination of TZD in oral dual therapy showed benefit in all-cause dementia and VaD. TZD activates the proliferator-activated receptor- $\gamma$ (PPAR-y) that has insulin sensitivity [22], and anti-inflammatory, anti-oxidative, anti-acetylcholinesterase and neuroprotective activity in vascular disease animal models [23]. It is known that TZDs may decrease recurrent stroke and related vascular events both in patients with T2D and even in those with insulin resistance without diabetes [24, 25]. Vascular dementia can also be caused by a series of small strokes. Our findings support that selecting TZDs as secondline therapy may be good option to prevent VaD. In AD, TZD dual combination except SU + TZD revealed the benefit in AD. The effect of TZDs on insulin sensitivity induces anti-inflammatory and anti-amyloidogenic effects in AD [26]. Further study may be helpful to show why combination of SU + TZD than that of Met + SU did not lower AD events.

The real-world benefit of TZD in dementia is supported by large population-based retrospective observational research with two Taiwan National Health Insurance datasets and one German general practice dataset [15-17]. Tseung, et al. showed that TZD ever-users versus never-users was associated with a lower risk of dementia (HR $=0.71695 \% \mathrm{Cl} 0.545-0.940)$ [17]. In a matched case-control German study, Bohlken, et al. showed that the risk of dementia in general practice, regardless of the prescription duration, was reduced in TZD ever-users versus never-users $(\mathrm{OR}=0.80,95 \% \mathrm{Cl} 0.68-0.95)$, but not for Met $(\mathrm{OR}=$ $0.96,95 \% \mathrm{Cl} 0.88-1.04)$, DPP-4i ( $\mathrm{OR}=0.99,95 \% \mathrm{Cl} 0.91-1.07)$ or SU $(\mathrm{OR}=1.03,95 \% \mathrm{Cl} 0.96-1.10)$, and it was increased in insulin users $(\mathrm{OR}=1.34,95 \% \mathrm{Cl} 1.24-$ 1.44) [16]. In combination with Met, Lu et al. reported that 204,323 Taiwan patients with T2D and $\geq 65$ years that MET + TZD was significantly superior to Met $+\mathrm{SU}$ in the risk of developing dementia $(\mathrm{HR}=0.56)$ [15]. On the other hand, a nationwide nested case-control study, enrolled from 1995 to 2012 , reported that TZD ever-users, including rosiglitazone, versus never-users did not have a significant odds of developing dementia (OR $=0.89,95 \% \mathrm{Cl} 0.76-1.03)$, but further analysis of dual therapy with TZD was not conducted [20]. In Korea, there are two TZDs, lobeglitazone and pioglitazone, approved by the Ministry of Food and Drug Safety. Rosiglitazone was excluded by enrolment starting in 2009 in our study due to controversy about its role in cardiovascular events [27]. The advantage of TZD for preventing any type of dementia becomes apparent in dual therapy.

DPP-4i increases the glucose-dependent insulin response and reduces glucagon secretion by inhibiting GLP-1 degradation [28]. Wium-Andersen, et al. showed DPP-4i ever-users had a lower odds of dementia than never-users (OR= 0.80, 95\% $\mathrm{Cl} 0.74-0.88$ ) and the Met + DPP-4i dual combination was associated with a lower odds of dementia than no anti-diabetes medication ( $\mathrm{OR}=0.70,95 \% \mathrm{Cl} 0.58-0.86)$ [20]. In subclasses of dementia, Kim, et al. demonstrated that DPP-4i new users versus SU new users over 60 years old had a lower risk of all-cause dementia and $\mathrm{AD}(\mathrm{HR}=0.66,95 \% \mathrm{Cl} 0.56-0.78$ and $\mathrm{HR}=0.64,95 \% \mathrm{Cl}=0.52-$ $0.79)$, but not $\mathrm{VaD}(\mathrm{HR}=0.56,95 \% \mathrm{Cl} 0.38-1.14)$ over 4 years [14]. Although a meta-analysis of three large randomized controlled trials of DPP-4i (the SAVORTIMI 53, EXAMINE, and TECOS trial) versus placebo showed no significant reduction in the risk of stroke [29], a predisposing factor for VaD, the median followup period (1.5 3 years) might be too short to see the difference in these events. On the other hand, Taiwan national data of those aged $\geq 50$ years by Chen et al. showed DPP-4i new users versus non DPP-4i users had a lower risk of all-cause dementia $(\mathrm{HR}=0.80,95 \% \mathrm{Cl} 0.68-0.88)$ and VaD $(\mathrm{HR}=0.61,95 \% \mathrm{Cl} 0.40-$ $0.68)$, but not $A D(H R=0.89,95 \% \mathrm{Cl} 0.71-1.27)$ with a mean duration of 7 years of follow-up. The difference between these studies may be attributed to their study designs, their demographics and their population sample sizes, as well as the duration of follow up. Compared to SU, a beneficial effect of DPP-4i on AD was more evident in dual therapy with Met in our study.

Also, the combination with insulin lost the benefits of protective dual therapy on dementia in our study (Suppl Table 4). The beneficial effect of DPP-4i and TZD as second line therapy on dementia went away in cases of insulin combination. This is consistent with the study by Bohlken, et al., where they showed that insulin was associated with an increased risk of developing dementia $(\mathrm{OR}=1.34,95 \% \mathrm{Cl} 1.24-1.44)$ and a combination with insulin was a risk factor of dementia [16]. A pooled analysis of 5 other cohorts also showed insulin users versus non-users were associated with an increased risk of new-onset dementia (pooled HR $=1.58,95 \% \mathrm{Cl}$ 1.18-2.12) [30]. Although patients treated with insulin are likely to have a longer duration of diabetes, poor glucose control and more comorbidities than those on oral hypoglycaemic agents, the association between dementia and insulin still remains high even after adjustment of these confounding factors. However, caution is needed in interpreting these observational studies. Insulin itself should not be mistaken as a cause of dementia. A meta-analysis of five observational studies reported a significantly increased risk of dementia in patients who had hypoglycaemic events (pooled OR $=1.68$, $95 \% \mathrm{Cl}$ 1.45-1.95) [31]. Several possible mechanisms have been suggested from animal and human studies [32-34], where hypoglycaemia might induce neuronal cell death in brain memory areas, increase adrenaline levels and cause endothelial dysfunction. People who take insulin injections among their diabetes drugs would have frequent events of hypoglycaemia and that could be one reason why TZD, DPP-4i and Met have better effects on dementia than insulin medication. 
There was no significant association between oral anti-diabetic medication and dementia type in case of monotherapy and more than dual therapy in our database. In monotherapy, Met usually should be the first-line choice in oral therapy for patient with T2D according to Korean guideline of diabetes management [35]. It was difficult to compare each group in monotherapy because there were many Met users on monotherapy and relatively few TZD and DPP-4i users in real world clinical setting. Also, it was difficult to find diabetic patients receiving with long-term and persistent triple or more therapy for the same reason.

\section{Limitations}

There were some limitations to this analysis. First, this was a retrospective observational study. Therefore, the actual mechanism of the association between anti-diabetic medications and dementia cannot be clarified. However, while randomized controlled trials (RCTs) are considered the best level of evidence and are the only study design that can establish causality, their role with their relatively short-term follow-up duration in understanding the relationships between diabetes medications and dementia is limited. To reduce the confounding factors of various treatments on disease prevention, we tried to increase the reliability of the data focusing on oral dual combination therapy by excluding mono and more than dual therapy in real world clinical setting. Second, discrepancies between the actual diagnosis and claim data might be possible. The accuracy of diagnoses in claim databases is debatable. T2D and dementia prevalence may be underestimated because only subjects seeking a medical evaluation can be identified. Third, sodium glucose co-transporter 2 (SGLT2) inhibitors and glucagon-like peptide 1 (GLP1) receptor agonists were not included in the analysis of this study, because of not commonly used during the observation period.

\section{Conclusions}

In conclusion, we investigated whether different types of anti-diabetic medications and treatment regimens (combinations of anti-diabetic drugs) were associated with the risk of developing dementia. Adding a TZD or DPP-4i instead of SU as second-line treatment to first-line metformin might be considered for delaying dementia. TZD combined with other than Met in dual therapy also had a significantly lower risk of dementia.

\section{Declarations}

\section{- Ethical Approval and Consent to participate}

All subjects provided written informed consent, and this study protocol was approved by the Institutional Review Board of the Sungkyunkwn University School of Medicine/Kangbuk Samsung Hospital (IRB No. 2018-01-036) and the Institutional Review Board of of the NHIS (number: NHIS-2019-1-218) . Informed consent was waived by the IRB.

\section{- Consent for publication}

All authors agreed to publication

\section{- Availability of data and materials}

Data are available from the Korea National Health Insurance Sharing Service

(https://nhiss.nhis.or.kr/bd/ay/bdaya001iv.do;jsessionid=KiOt6ilaTGXMmR1mbeeA9Ax7nJjIYDsKr4UJAJvHhNyo511E0PovM1WfrGSaegL6.primrose22_servle For more information, please contact Dr. Cheol-Young Park (cydoctor@chol.com). The datasets supporting the conclusions of this article are included within the article and its additional file.

\section{- Competing interests}

The authors declare no conflicts of interest.

\section{- Funding}

This study was supported by the Chong Kun Dang Pharmaceutical Corp., Seoul, Republic of Korea.

The sponsor had no role in the writing of the manuscript or in the decision to submit the manuscript for publication.

\section{- Authors' contributions}

WK, JN, KH, and CP designed the study and all were involved in data collection and study execution. JN and CP provided guidance on the data analysis and contributed to the interpretation of the results. KH contributed to the statistical analysis. CP took part in the study supervision and coordination and obtained funding for the study. WK drafted the manuscript. All authors read and took part in revising the manuscript for content and approved the final manuscript.

\section{- Acknowledgements}

This study utilizes the data of the National Health Insurance Service and results are unrelated to the opinion of the National Health Insurance Service.

\section{- Authors' information}

Won Jun Kim, Email: kozmozman@naver.com 
Jung Hyun Noh, Email: jhnoh@paik.ac.kr

Kyungdo Han, Email: hkd917@naver.com

Cheol-Young Park, Email: cydoctor@chol.com

\section{Abbreviations}

AD Alzheimer's dementia

AGI Alpha-glucosidase inhibitor

DPP-4i Dipeptidyl peptidase-4 inhibitor

IDF International Diabetes Foundation

Megl Meglitinide

Met Metformin

SU Sulfonylurea

TZD Thiazolidinedione

T2D Type 2 diabetes mellitus

VaD Vascular dementia

\section{References}

1. Saeedi P, Petersohn I, Salpea P, Malanda B, Karuranga S, Unwin N, et al.; IDF Diabetes Atlas Committee. (2019) Global and regional diabetes prevalence estimates for 2019 and projections for 2030 and 2045: Results from the International Diabetes Federation Diabetes Atlas, 9th edition Diabetes Res Clin Pract. 2019;157: 107843. doi: 10.1016/j.diabres.2019.107843.

2. Defronzo RA. Banting Lecture. From the triumvirate to the ominous octet: a new paradigm for the treatment of type 2 diabetes mellitus. Diabetes. 2009;58(4):773-795. doi: 10.2337/db09-9028.

3. Ko SH, Kim DJ, Park JH, Park CY, Jung CH, Kwon HS, et al.; Task Force Team for Diabetes Fact Sheet of the Korean Diabetes Association. Trends of antidiabetic drug use in adult type 2 diabetes in Korea in 2002-2013: Nationwide population-based cohort study. Medicine. 2016;95(27):e4018. doi: 10.1097/MD.0000000000004018 PMID: 27399082

4. Wilkinson S, Douglas I, Stirnadel-Farrant H, Fogarty D, Pokrajac A, Smeeth L, et al. Changing use of antidiabetic drugs in the UK: trends in prescribing 2000-2017. BMJ Open. 2018;8(7):e022768. doi:10.1136/bmjopen-2018-022768.

5. Davies MJ, D’Alessio DA, Fradkin J, Kernan WN, Mathieu C, Mingrone G, et al. Management of Hyperglycemia in Type 2 Diabetes, 2018. A Consensus Report by the American Diabetes Association (ADA) and the European Association for the Study of Diabetes (EASD). Diabetes Care. 2018;41(12):26692701. doi: $10.2337 /$ dci18-0033.

6. Ott A, Stolk R P, Hofman A, van Harskamp F, Grobbee D E, Breteler M M. Association of diabetes mellitus and dementia: the Rotterdam Study. Diabetologia..1996;39(11):1392-1397. doi: 10.1007/s001250050588.

7. Huang CC, Chung CM, Leu HB, Lin LY, Chiu CC, Hsu CY, et al. Diabetes mellitus and the risk of Alzheimer's disease: a nationwide population-based study. PLoS One. 2014;9(1):e87095. doi: 10.1371/journal.pone.0087095.

8. Ohara T, Doi Y, Ninomiya T, Hirakawa Y, Hata J, Iwaki T, et al. Glucose tolerance status and risk of dementia in the community: the Hisayama Study. Neurology. 2011;77(12):1126-1134. doi: 10.1212/WNL.0b013e31822f0435.

9. Gudala K, Bansal D, Schifano F, Bhansali A. Diabetes Mellitus and Risk of Dementia: A Meta-Analysis of Prospective Observational Studies. J diabetes Investig. 2013;4(6):640-650. doi: 10.1111/jdi.12087.

10. Ninomiya T. Diabetes mellitus and dementia. Curr Diab Rep. 2014;14(5):487. doi: 10.1007/s11892-014-0487-z.

11. Areosa Sastre A, Vernooij RW, Gonzalez-Colaco Harmand M, Martinez G. Effect of the treatment of type 2 diabetes mellitus on the development of cognitive impairment and dementia. Cochrane Database Syst Rev. 2017;6(6):CD003804. doi: 10.1002/14651858.CD003804.pub2.

12. Verma N, Despa F. Contributing Factors to Diabetic Brain Injury and Cognitive Decline. Diabetes Metab. 2019;43(5):560-567. doi: 10.4093/dmj.2019.0153.

13. Orkaby AR, Cho K, Cormack J, Gagnon DR, Driver JA. Metformin vs sulfonylurea use and risk of dementia in US veterans aged $\geq 65$ years with diabetes. Neurology. 2017;89(18):1877-1885. doi: 10.1212/WNL.0000000000004586.

14. Kim YG, Jeon JY, Kim HJ, Kim DJ, Lee KW, Moon SY, et al. Risk of dementia in older patients with type 2 diabetes on dipeptidyl-peptidase IV inhibitors versus sulfonylureas: a real-world population-based cohort study. J Clin Med. 2018;8(1):28. doi: 10.3390/jcm8010028.

15. Lu CH, Yang CY, Li CY, Hsieh CY, Ou HT. Lower risk of dementia with pioglitazone, compared with other second-line treatments, in metformin-based dual therapy: a population-based longitudinal study. Diabetologia. 2018;61(3):562-573. doi: 10.1007/s00125-017-4499-5. 
16. Bohlken J, Jacob L, Kostev K. Association between the use of antihyperglycemic drugs and dementia risk: a case-control study. J Alzheimers Dis. 2018;66(2):725-732. doi: 10.3233/JAD-180808.

17. Tseng $\mathrm{CH}$. Pioglitazone reduces dementia risk in patients with type 2 diabetes mellitus: a retrospective cohort analysis. J Clin Med. 2018;7(10):306. doi: $10.3390 / \mathrm{jcm} 7100306$.

18. Tseng CH. Metformin and the Risk of Dementia in Type 2 Diabetes Patients. Aging Dis. 2019;10(1):37-48. doi: 10.14336/AD.2017.1202.

19. Chen KC, Chung CH, Lu CH, Tzeng NS, Lee CH, Su SC, et al. Association between the Use of Dipeptidyl Peptidase 4 Inhibitors and the Risk of Dementia among Patients with Type 2 Diabetes in Taiwan. J Clin Med. 2020;9(3):660. doi: 10.3390/jcm9030660.

20. Wium-Andersen IK, Osler M, Jorgensen MB, Rungby J, Wium-Andersen MK. Antidiabetic medication and risk of dementia in patients with type 2 diabetes. A nested case-control study. Eur. J. Endocrinol. 2019;181(5):499-507. doi: 10.1530/EJE-19-0259.

21. Song SO, Jung CH, Song YD, Park CY, Kwon HS, Cha BS, et al. Background and data configuration process of a nationwide population-based study using the Korean National Health Insurance System. Diabetes Metab J. 2014;38(5):395-403. doi: 10.4093/dmj.2014.38.5.395.

22. Inzucchi SE. Oral antihyperglycemic therapy for type 2 diabetes: scientific review. JAMA. 2002;287(3):360-372. doi: 10.1001/jama.287.3.360.

23. Sharma B, Singh N. Behavioral and biochemical investigations to explore pharmacological potential of PPAR-gamma agonists in vascular dementia of diabetic rats. Pharmacol Biochem Behav. 2011;100(2):320-329. doi: 10.1016/j.pbb.2011.08.020.

24. Dormandy JA, Charbonnel B, Eckland DJ, Erdmann E, Massi-Benedetti M, Moules IK, et al. Secondary prevention of macrovascular events in patients with type 2 diabetes in the PROactive study (PROspective pioglitAzone Clinical Trial In macroVascular Events): a randomized controlled trial. Lancet. 2005;366(9493):1279-1289. doi: 10.1016/S0140-6736(05)67528-9.

25. Kernan WN, Viscoli CM, Furie KL, Young LH, Inzucchi SE, Gorman M, et al. Pioglitazone after ischemic stroke or transient ischemic attack. N Engl J Med. 2016;374(14):374:1321-1331. doi: 10.1056/NEJMoa1506930.

26. Heneka MT, Reyes-Irisarri E, Hull M, P Kummer M. Impact and therapeutic potential of PPARs in Alzheimer's disease. Curr Neuropharmacol. 2011;9(4):643-650. doi: 10.2174/157015911798376325.

27. Nissen SE, Wolski K. Effect of rosiglitazone on the risk of myocardial infarction and death from cardiovascular causes. N Engl J Med. 2007;356(24):24572471. doi: 10.1056/NEJMoa072761.

28. Lovshin JA, Drucker DJ. Incretin-based therapies for type 2 diabetes mellitus. Nat Rev Endocrinol. 2009;5(5):262-269. doi: 10.1038/nrendo.2009.48.

29. Mannucci E,Mosenzon O, Avogaro A. Analyses of Results From Cardiovascular Safety Trials With DPP-4 Inhibitors: Cardiovascular Outcomes, Predefined Safety Outcomes, and Pooled Analysis and Meta-analysis Diabetes Care. 2016;39(Suppl 2):S196-S204. doi: 10.2337/dcS15-3024.

30. Weinstein G, Davis-Plourde KL, Conner S, Himali JJ, Beiser AS, Lee A, et al. Association of metformin, sulfonylurea and insulin use with brain structure and function and risk of dementia and Alzheimer's disease: pooled analysis from 5 cohorts. PLoS One. 2019;14(2):e0212293. doi: 10.1371/journal.pone.0212293.

31. Mattishent K, Loke YK. Bi-directional interaction between hypoglycaemia and cognitive impairment in elderly patients treated with glucose-lowering agents: a systematic review and meta-analysis. Diabetes Obes Metab. 2016;18(2):135-141. doi: 10.1111/dom.12587.

32. Languren G, Montiel T, Julio-Amilpas A, Massieu L. Neuronal damage and cognitive impairment associated with hypoglycemia: an integrated view. Neurochem Int. 2013;63(4):331-343. doi: 10.1016/j.neuint.2013.06.018.

33. Fisher BM, Hepburn DA, Smith JG, Frier BM. Responses of peripheral blood cells to acute insulin-induced hypoglycaemia in humans: effect of alphaadrenergic blockade. Horm Metab Res Suppl. 1992;26:109-110.

34. Wright RJ, Newby DE, Stirling D, Ludlam CA, Macdonald IA, Frier BM. Effects of acute insulin-induced hypoglycemia on indices of inflammation: putative mechanism for aggravating vascular disease in diabetes. Diabetes Care. 2010;33(7):1591-1597. doi: 10.2337/dc10-0013.

35. Kim MK, Ko SH, Kim BY, Kang ES, Noh J, Kim SK, et al., Committee of Clinical Practice Guidelines, Korean Diabetes Association. 2019 Clinical Practice Guidelines for Type 2 Diabetes Mellitus in Korea. Diabetes Metab J. 2019;43(4):398-406. doi: 10.4093/dmj.2019.0137.

36. Moran C, Callisaya ML, Srikanth V, Arvanitakis Z. Diabetes therapies for dementia. Curr Neurol Neurosci Rep. 2019;19(8):58. doi: 10.1007/s11910-0190973-4 .

\section{Tables}

Table 1. Baseline characteristics of Combination therapy group without Insulin. Data are presented as mean \pm S.D. or percent. DM: Diabetes Mellitus, SBP: Systolic Blood Pressure, DBP: Diastolic Blood Pressure, eGFR: Estimated Glomerular Filtration Rate. 


\begin{tabular}{|c|c|c|c|c|c|c|c|c|}
\hline & Met + SU & Met + DPP-4i & Met + TZD & Met + AGI & $S U+T Z D$ & $\mathrm{SU}+\mathrm{AGI}$ & Other dual therapy & P-value \\
\hline Number & 419,442 & 134,195 & 37,401 & 12,320 & 53,382 & 30,261 & 14,192 & \\
\hline Age (year) & $60.7 \pm 10.2$ & $57.9 \pm 10.1$ & $58.7 \pm 9.7$ & $61.8 \pm 10.2$ & $60.1 \pm 9.7$ & $63.7 \pm 10.0$ & $61.4 \pm 10.2$ & $<.0001$ \\
\hline Gender, male (\%) & 55.9 & 56.1 & 57.1 & 51.3 & 57.6 & 54.6 & 56.4 & $<.0001$ \\
\hline DM duration, $\geq 5$ yrs(\%) & 91.4 & 85.7 & 90.6 & 92.1 & 96.8 & 96.6 & 93.4 & $<.0001$ \\
\hline Income, low 20\% (\%) & 23.3 & 21.00 & 20.3 & 22.3 & 21.3 & 23.0 & 21.6 & $<.0001$ \\
\hline Hypertension (\%) & 65.1 & 60.0 & 61.3 & 65.4 & 64.3 & 67.7 & 65.6 & $<.0001$ \\
\hline Dyslipidemia (\%) & 47.0 & 56.0 & 60.0 & 51.7 & 57.3 & 48.0 & 53.7 & $<.0001$ \\
\hline Smoking (\%) & & & & & & & & $<.0001$ \\
\hline Non & 59.2 & 57.2 & 58.4 & 62.7 & 58.1 & 62.3 & 59.3 & \\
\hline Ex & 18.1 & 20.3 & 21.3 & 18.5 & 19.2 & 18.1 & 20.8 & \\
\hline Current & 22.7 & 22.5 & 20.3 & 18.9 & 22.7 & 19.7 & 19.9 & \\
\hline Drinking (\%) & & & & & & & & $<.0001$ \\
\hline Non & 63.4 & 62.6 & 61.5 & 68.6 & 62.4 & 68.2 & 67.4 & \\
\hline Mild & 27.9 & 29.1 & 30.3 & 24.7 & 29.2 & 24.5 & 25.7 & \\
\hline Heavy & 8.8 & 8.4 & 8.2 & 6.7 & 8.4 & 7.3 & 7.0 & \\
\hline Regular exercise (\%) & 21.9 & 22.9 & 24.3 & 22.2 & 23.0 & 22.1 & 23.4 & $<.0001$ \\
\hline Body Mass Index $\left(\mathrm{kg} / \mathrm{m}^{2}\right)$ & $25.2 \pm 3.2$ & $25.2 \pm 3.3$ & $25.6 \pm 3.3$ & $24.6 \pm 3.3$ & $25.8 \pm 3.5$ & $24.7 \pm 3.2$ & $24.7 \pm 3.3$ & $<.0001$ \\
\hline $\mathrm{SBP}(\mathrm{mmHg})$ & $129.6 \pm 15.7$ & $126.9 \pm 15.2$ & $126.9 \pm 14.9$ & $127.7 \pm 15.4$ & $128.5 \pm 15.2$ & $129.3 \pm 15.9$ & $128.2 \pm 15.9$ & $<.0001$ \\
\hline $\mathrm{DBP}(\mathrm{mmHg})$ & $78.9 \pm 9.9$ & $77.7 \pm 9.9$ & $77.3 \pm 9.7$ & $77.7 \pm 9.7$ & $77.5 \pm 9.8$ & $77.9 \pm 10.0$ & $77.4 \pm 10.1$ & $<.0001$ \\
\hline Total cholesterol (mg/dL) & $191.4 \pm 41.0$ & $183.4 \pm 41.9$ & $187.3 \pm 40.8$ & $186.1 \pm 40.2$ & $191.6 \pm 42.1$ & $190.2 \pm 42.5$ & $183.9 \pm 41.3$ & $<.0001$ \\
\hline Fasting Glucose (mg/dL) & $147.3 \pm 50.4$ & $142.6 \pm 46.3$ & $130.9 \pm 40.0$ & $133.4 \pm 41.1$ & $143.0 \pm 48.7$ & $143.8 \pm 49.6$ & $143.8 \pm 48.1$ & $<.0001$ \\
\hline eGFR $\left(\mathrm{mL} / \mathrm{min} / \mathrm{m}^{2}\right)$ & $84.4 \pm 35.0$ & $86.3 \pm 37.4$ & $85.1 \pm 39.1$ & $82.2 \pm 31.1$ & $82.5 \pm 33.9$ & $79.0 \pm 38.6$ & $80.0 \pm 40.6$ & $<.0001$ \\
\hline
\end{tabular}

Table 2. Incidence rates and hazard ratios of dementia, Alzheimer's dementia, and vascular dementia by combination of anti-diabetic medication exposure. N: cases followed, n: incident cases of dementia, PY: Person-Years, HR: hazard ratio, Cl: confidence interval. SU: Sulfonylurea, Met: Metformin, TZD:

thiazolidinediones, DPP-4i: dipeptidyl peptidase 4 inhibitor, Megl: Meglitinide, AGI: alpha-glucosidase inhibitor, MODEL 1: adjusted for gender, income, hypertension, dyslipidemia, duration of diabetes, Model 1: unadjusted, MODEL 2: adjusted for Model 2 + smoking, drinking, exercise, body mass index, fasting glucose, estimated glomerular filtration rate 


\begin{tabular}{|c|c|c|c|c|c|c|c|c|c|}
\hline & \multicolumn{9}{|c|}{ Without Insulin } \\
\hline & \multirow[t]{2}{*}{$\mathrm{N}$} & & \multirow[t]{2}{*}{$\mathrm{n}$} & \multirow[t]{2}{*}{ PY } & & \multirow{2}{*}{$\begin{array}{l}\text { Incident Rate } \\
\text { (Per 1,000 } \\
\text { PY) }\end{array}$} & \multirow{2}{*}{$\begin{array}{l}\text { MODEL } 1 \\
\text { HR }(95 \% \mathrm{Cl})\end{array}$} & \multirow{2}{*}{$\begin{array}{l}\text { MODEL } 2 \\
\text { HR (95\% Cl) }\end{array}$} & \multirow{2}{*}{$\begin{array}{l}\text { MODEL } 3 \\
\text { HR }(95 \% \mathrm{Cl})\end{array}$} \\
\hline & & & & & & & & & \\
\hline \multicolumn{10}{|l|}{ All-cause dementia } \\
\hline Met + SU & 419,442 & & 31,770 & 2936018.5 & & 10.82 & 1 (ref.) & 1 (ref.) & 1 (ref.) \\
\hline Met + DPP-4i & 134,195 & & 6,046 & 887640.41 & & 6.81 & $\begin{array}{l}0.656(0.638 \\
0.674)\end{array}$ & $0.905(0.88,0.931)$ & $\begin{array}{l}0.904(0.879 \\
0.929)\end{array}$ \\
\hline Met + TZD & 37,401 & & 1,760 & 272680.1 & & 6.45 & $\begin{array}{l}0.587(0.559 \\
0.615)\end{array}$ & $\begin{array}{l}0.773(0.737 \\
0.811)\end{array}$ & $\begin{array}{l}0.804(0.767 \\
0.844)\end{array}$ \\
\hline Met + AGI & 12,320 & & 1,070 & 86643.5 & & 12.35 & $\begin{array}{l}1.137(1.070 \\
1.208)\end{array}$ & $\begin{array}{l}1.029 \text { (0.968, } \\
1.093)\end{array}$ & $\begin{array}{l}1.014(0.954 \\
1.077)\end{array}$ \\
\hline$S U+T Z D$ & 53,382 & & 3,522 & 388984.35 & & 9.05 & $\begin{array}{l}0.820(0.792 \\
0.849)\end{array}$ & $\begin{array}{l}0.934(0.902 \\
0.967)\end{array}$ & $\begin{array}{l}0.962(0.929 \\
0.996)\end{array}$ \\
\hline $\mathrm{SU}+\mathrm{AGI}$ & 30,261 & & 3,267 & 211409.38 & & 15.45 & $\begin{array}{l}1.419(1.369 \\
1.471)\end{array}$ & $\begin{array}{l}1.044(1.007 \\
1.082)\end{array}$ & $\begin{array}{l}1.021(0.985 \\
1.059)\end{array}$ \\
\hline Other dual therapy & 14,192 & & 1,164 & 96847.2 & & 12.02 & $1.122(1.059,1.19)$ & $\begin{array}{l}1.059 \text { (0.998, } \\
1.122)\end{array}$ & $\begin{array}{l}1.045(0.985 \\
1.108)\end{array}$ \\
\hline \multicolumn{10}{|l|}{$\begin{array}{l}\text { Alzheimer's } \\
\text { dementia }\end{array}$} \\
\hline Met + SU & 419,442 & & 25,382 & $2,936,018.5$ & & 8.65 & 1 (ref.) & 1 (ref.) & 1 (ref.) \\
\hline Met + DPP-4i & 134,195 & & 4,855 & $887,640.41$ & & 5.47 & $\begin{array}{l}0.665(0.645 \\
0.686)\end{array}$ & $\begin{array}{l}0.925(0.897 \\
0.954)\end{array}$ & $\begin{array}{l}0.922(0.894 \\
0.951)\end{array}$ \\
\hline Met + TZD & 37,401 & & 1,417 & $272,680.1$ & & 5.20 & $\begin{array}{l}0.589 \text { (0.559, } \\
0.622)\end{array}$ & $\begin{array}{l}0.784(0.743 \\
0.827)\end{array}$ & $0.812(0.77,0.857)$ \\
\hline Met + AGI & 12,320 & & 848 & $86,643.5$ & & 9.79 & $\begin{array}{l}1.127(1.052, \\
1.207)\end{array}$ & $\begin{array}{l}1.017 \text { (0.950, } \\
1.089)\end{array}$ & $\begin{array}{l}1.001(0.935 \\
1.072)\end{array}$ \\
\hline$S U+T Z D$ & 53,382 & & 2,833 & $388,984.35$ & & 7.28 & $\begin{array}{l}0.823(0.791 \\
0.855)\end{array}$ & $0.943(0.907,0.98)$ & $\begin{array}{l}0.971(0.934 \\
1.010)\end{array}$ \\
\hline $\mathrm{SU}+\mathrm{AGI}$ & 30,261 & & 2,588 & $211,409.38$ & & 12.24 & $\begin{array}{l}1.404(1.348 \\
1.462)\end{array}$ & $\begin{array}{l}1.027(0.986 \\
1.069)\end{array}$ & $\begin{array}{l}1.006(0.966 \\
1.047)\end{array}$ \\
\hline Other dual therapy & 14,192 & & 947 & $96,847.2$ & & 9.78 & $\begin{array}{l}1.145(1.073 \\
1.222)\end{array}$ & $1.08(1.012,1.153)$ & $\begin{array}{l}1.067(1.000, \\
1.138)\end{array}$ \\
\hline \multicolumn{10}{|l|}{ Vascular dementia } \\
\hline Met + SU & 419,442 & & 4,985 & 2936018.5 & & 1.70 & 1 (ref.) & 1 (ref.) & 1 (ref.) \\
\hline Met + DPP-4i & 134,195 & & 942 & 887640.41 & & 1.06 & $\begin{array}{l}0.647(0.603 \\
0.694)\end{array}$ & $\begin{array}{l}0.862(0.804 \\
0.925)\end{array}$ & $\begin{array}{l}0.865(0.806 \\
0.928)\end{array}$ \\
\hline Met + TZD & 37,401 & & 259 & 272680.1 & & 0.95 & $\begin{array}{l}0.551 \\
0.624)\end{array}$ & $\begin{array}{l}0.695(0.613 \\
0.788)\end{array}$ & $\begin{array}{l}0.725(0.640 \\
0.822)\end{array}$ \\
\hline Met + AGI & 12,320 & 178 & & 86643.5 & 2.05 & & $\begin{array}{l}1.206(1.039 \\
1.401)\end{array}$ & $\begin{array}{l}1.107(0.953 \\
1.285)\end{array}$ & $\begin{array}{l}1.098(0.946 \\
1.276)\end{array}$ \\
\hline$S U+T Z D$ & 53,382 & 543 & & 388984.35 & 1.40 & & $\begin{array}{l}0.808(0.739 \\
0.883)\end{array}$ & $\begin{array}{l}0.890(0.814 \\
0.973)\end{array}$ & $\begin{array}{l}0.911(0.833 \\
0.995)\end{array}$ \\
\hline $\mathrm{SU}+\mathrm{AGI}$ & 30,261 & 521 & & 211409.38 & 2.46 & & $\begin{array}{l}1.444(1.320 \\
1.581)\end{array}$ & $\begin{array}{l}1.100(1.005 \\
1.204)\end{array}$ & $\begin{array}{l}1.076(0.983 \\
1.178)\end{array}$ \\
\hline Other dual therapy & 14,192 & 184 & & 96847.2 & 1.90 & & $\begin{array}{l}1.130(0.975 \\
1.309)\end{array}$ & $\begin{array}{l}1.065(0.919 \\
1.234)\end{array}$ & $\begin{array}{l}1.050(0.906 \\
1.217)\end{array}$ \\
\hline
\end{tabular}

Table 3. Incidence rates and hazard ratios of dementia, Alzheimer's dementia, and vascular dementia by TZD and non-TZD based oral dual therapy exposure. $\mathrm{N}$ : cases followed, $\mathrm{n}$ : incident cases of dementia, PY: Person-Years, HR: hazard ratio, Cl: confidence interval. TZD: thiazolidinediones, MODEL 1: adjusted for gender, income, hypertension, dyslipidemia, duration of diabetes, Model 1: unadjusted, MODEL 2: adjusted for Model 2 + smoking, drinking, exercise, body mass index, fasting glucose, estimated glomerular filtration rate 


\begin{tabular}{|c|c|c|c|c|c|c|c|}
\hline & \multirow[t]{2}{*}{$\mathrm{N}$} & \multirow[t]{2}{*}{$\mathrm{n}$} & \multirow[t]{2}{*}{ PY } & \multirow[t]{2}{*}{ Incident Rate } & \multirow{2}{*}{$\begin{array}{l}\text { MODEL } 1 \\
\text { HR }(95 \% \mathrm{Cl})\end{array}$} & \multirow{2}{*}{$\begin{array}{l}\text { MODEL } 2 \\
\text { HR }(95 \% \mathrm{Cl})\end{array}$} & \multirow{2}{*}{$\begin{array}{l}\text { MODEL } 3 \\
\text { HR }(95 \% \mathrm{Cl})\end{array}$} \\
\hline & & & & & & & \\
\hline \multicolumn{8}{|c|}{ All-cause dementia } \\
\hline without TZD & 609892 & 43266 & 3604967.31 & 12.00177319 & 1 (ref.) & 1 (ref.) & 1 (ref.) \\
\hline with TZD & 91301 & 5333 & 574063.13 & 9.289919037 & $0.76(0.739,0.782)$ & $0.886(0.861,0.912)$ & $0.918(0.892,0.944)$ \\
\hline \multicolumn{8}{|c|}{ Alzheimer's dementia } \\
\hline without TZD & 609892 & 34579 & 3604967.31 & 9.592042597 & 1 (ref.) & 1 (ref.) & 1 (ref.) \\
\hline with TZD & 91301 & 4291 & 574063.13 & 7.47478766 & $0.761(0.737,0.785)$ & $0.894(0.866,0.923)$ & $0.925(0.896,0.955)$ \\
\hline \multicolumn{8}{|c|}{ Vascular dementia } \\
\hline without TZD & 609892 & 6799 & 3604967.31 & 1.88600878 & 1 (ref.) & 1 (ref.) & 1 (ref.) \\
\hline with TZD & 91301 & 813 & 574063.13 & 1.416220547 & $0.74(0.688,0.795)$ & $0.832(0.774,0.895)$ & $0.859(0.798,0.924)$ \\
\hline
\end{tabular}

\section{Figures}

Total $\mathrm{N}$ of type 2 diabetes $=2,703,713$

Korean NHIS Claim database and Health Screenings from 2009 to 2012

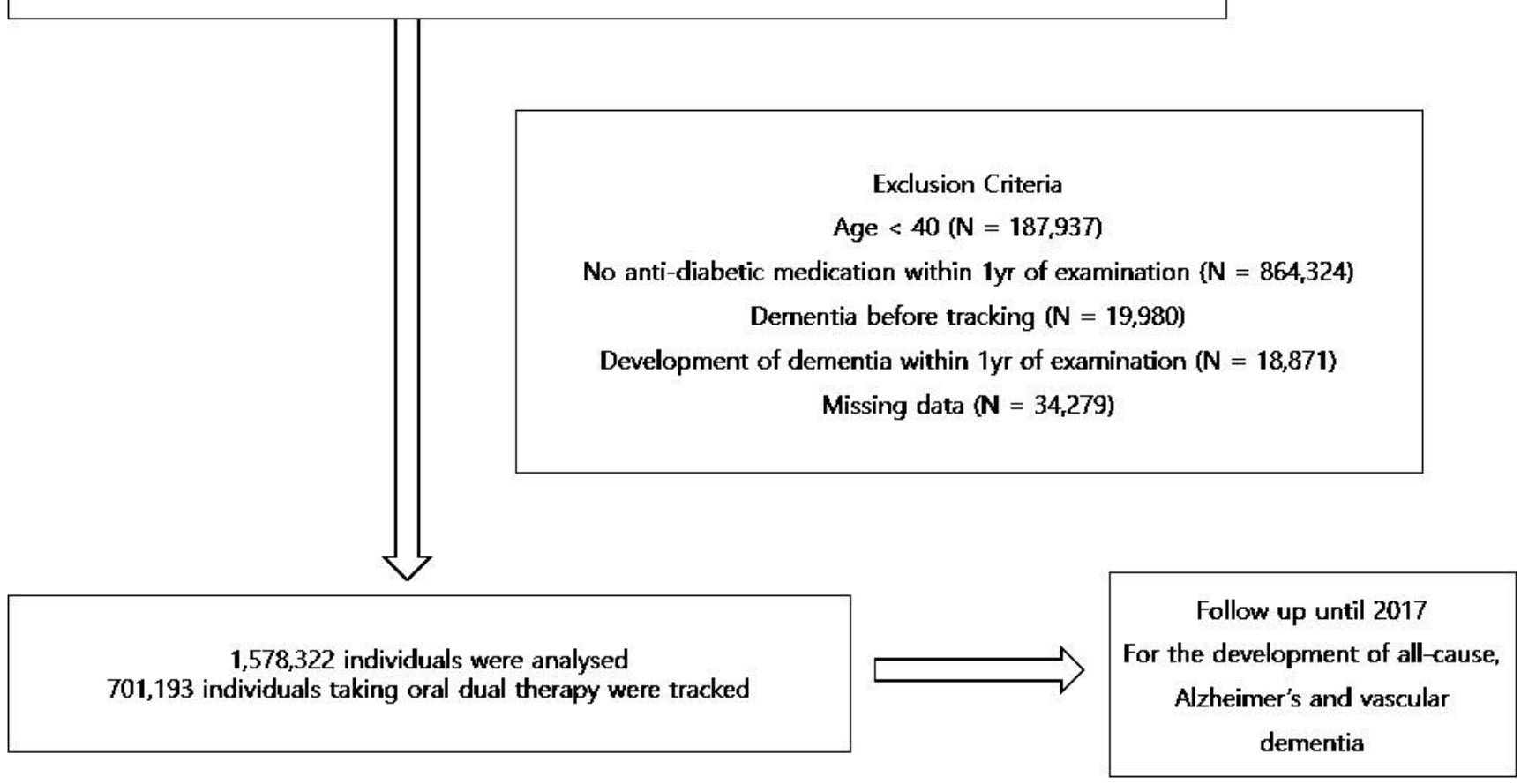

Figure 1

Flow chart of the sample selection process 
Total $\mathrm{N}$ of type 2 diabetes $=2,703,713$

Korean NHIS Claim database and Health Screenings from 2009 to 2012

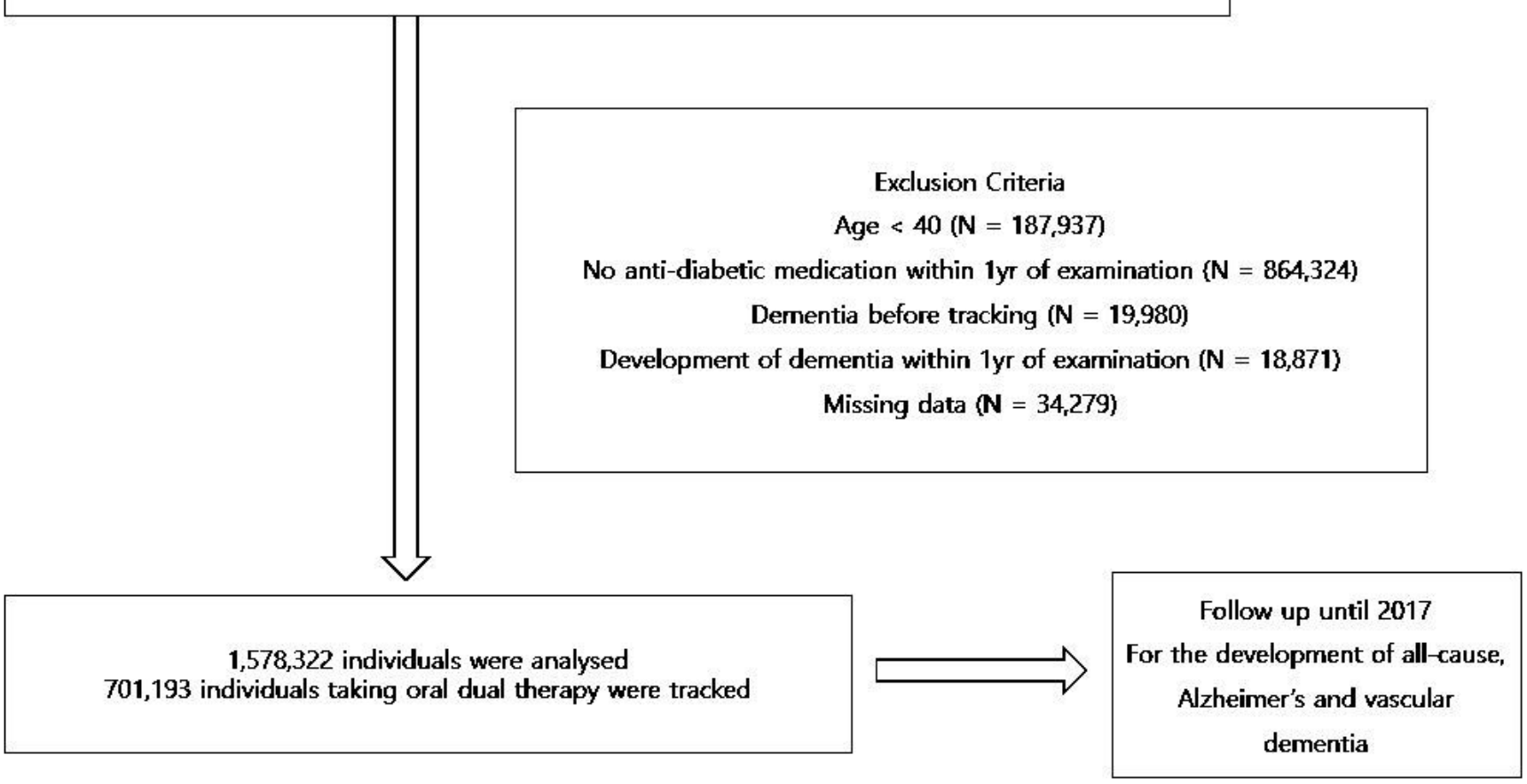

Figure 1

Flow chart of the sample selection process

\section{Supplementary Files}

This is a list of supplementary files associated with this preprint. Click to download.

- LaTeXsupportingfile.docx

- LaTeXsupportingfile.docx 